\title{
Value Research of Individualized Pursuit of Art Design
}

\author{
Boyang Li \\ School of Communication, Nanchang Institute of Technology, Nanchang Institute of Technology, Nanchang \\ City, Jiangxi Province, 330044
}

Keywords: Individualized pursuit of art design; Natural value limitation; Value research

\begin{abstract}
With the great promotion of the strategic transformation of the cultural industry at present, the phenomenon of mass production of various kinds of products occurs in the process of increasing economy of our country. While pursuing the production of high efficiency, we should also pay attention to the individualized demands of the products. But at present, our country is under the new-type times background of social progress, cultural diversity and the pursuit of individuality; people have clear gaps in terms of the consumption view. Suppose that all the products entering the market are mass-produced, they will not win favor from the consumers. Therefore, in this era background, people's art design requirements are constantly improving. In order to strive for the large-scale market, we must take into account consumers' demands for individualized products before production. In this paper, the author analyzes the influencing factors of the individualized pursuit of art design and the conditions that need to be met, and gives a full exposition of the value of artistic individualization.
\end{abstract}

\section{Introduction}

At present, China's economy and the society are in the process of rapid development, people's quality of life has also risen to a new height. Accordingly, people's individualized requirements for art design have also been improved. The previous mass products lack competitiveness; products without characteristics are difficult to meet the actual needs of the work. Therefore, reasonable and effective strategies should be developed on the basis of the social and economic development and people's improved appreciation taste. In the production process, keep in mind the importance of individualized art design of products. Such products can meet people's growing demands for the consumption quality and provide more artistic colors for people's lives.

\section{Overview of Individualized Pursuit of Art Design}

When modern people buy products, what they are concerned about the most is whether the product design is novel; products with individualized features can surprise people and arouse people's longing for beauty. On the contrary, if the product design is old-fashioned and lacks the vivid and new features, it is difficult to meet people's pursuit of art and the product market will not reach expectations. For the art designers, they should regard the handicraft production design as an important part of product design, perfectly show the distinctive features of the human characteristics and try to immerse the aesthetic art ideas of the subject into the works in the design process.

The connotation of individualized art design will be analyzed. It will also mention how to redesign the previous art design so as to meet its rationality. Re-design is different from the inherent concept of people. It is not the plagiarism of art creation. Instead, it is the redesign and recreation of the entire arts work on the basis of respecting the design of the original works, coupled with historical and cultural, economic values and other elements. The art redesign is of great significance to the promotion of local culture and the promotion of public art. The individualized art design can fully restore the original works. Coupled with the new elements, it can make consumers to enjoy the pictures more in line with the beauty of the times.

The characteristics of the individualization of the art design is that it can beautify the living environment around the consumers and meet people's pursuit of aesthetics. The products can fully 
demonstrate their own obvious characteristics in terms of design. First of all, the art design emphasizes the organic unity of culture and nature. The peaceful coexistence of man and nature enables the works of art to be spread smoothly on a global scale. Therefore, people's artistic creation must be carried out without affecting the environment. Once it causes inevitable persecution to the environment, any artwork will be swallowed by the harsh environment. In addition, the art design should be the unity of aesthetics and practicality. If the works of art only has aesthetics, its value will not be too high. Only when it is both beautiful and can meet some practical needs of people, its art design can be called superior.

There are many factors that affect the individuality of art works. If the designer wants to improve his design ability, he must have a profound understanding of these factors, and then come up with practical solutions from various aspects, and constantly improve his design level.

First of all, everyone has his own design style, which will limit the art design. The fixed design pattern will be formed in the long-term design and development and he can not give full play to his creativity. Another important factor is that the designer has always been guided by the traditional design patterns and loses his understanding of the works of art, so it is difficult for him to design outstanding works. Finally, it is difficult for the designer to combine the practicality and aesthetics of the works of art, so that the works designed by him either lack practicality or aesthetics.

\section{Limitation of Natural Value of Individualized Pursuit of Art Design}

Traditional handicraft technology lacks the standard production requirements. The traditional handicraft technology in our country has always had the following problems: low productivity, multiple natural price limits. According to the relevant statistics, the traditional handicraft technology has no standardized requirements in the design, which leads to the greater gap of the abilities between the product designers and producers. It is difficult to form the formal unified production processes and design standards. It is undeniable that the traditional handmade art products have the high artistic ornamental and individualized features, but there are no specific processes and standards in the production and operation process. It causes that after the products have any problems, it is difficult to conduct timely and effective treatment, thus leading to many problems to after-sale service. It is an important factor that influences the development of the artwork industry. The traditional handmade technology itself has the artistic features such as being non-normative, arbitrary and broad. Therefore, on the one hand, the handicraft products generally have the typical personality traces of the creators. On the other hand, out of the technological uniqueness of the traditional processing, it leads to certain man-hour differences of the processed products; the man-hour cannot be the same. In addition, after these individualized products of the art design are input to the society as the commodities, their quantity is limited, which cannot satisfy the demands of the social development for materials. These individualized products of the art design can only be provided for a small part of art aesthetics lovers and artwork collectors. It is difficult to meet people's basic needs of the materials in the realistic life. Therefore, the individualized workshop production model completely dependent on art design will result in the backwardness of the social productivity.

\section{Conditions to be Satisfied in the Individualized Pursuit of Art Design}

Excellent works of art can perfectly combine the history and culture with modern science and technology. The works in mass production through the modern technology can be widely circulated. And the individualized artworks can be known to more people and finally loved by the public. At present, some designers are only in the pursuit of the individuality of art design works, but neglect that it cannot be produced in mass batches, which leads to the problem in the product circulation. However excellent the art design works is, if it cannot be found by the public, it is still covered by dust. Therefore, the mass production of the art design works is a prerequisite for individuality. If designers want their works to be accepted by the public, they have to take into account whether the works of art is practical in design. Only the art design works with practicality can be accepted by 
more public and become the enduring perfect works.

The individualized art and design work should be centered on the feelings of consumers, because consumers' evaluation of the art design works can determine the value of the work; only the design works recognized by consumers can own the permanent vitality. Therefore, the designer should not ignore the consumers' subjective feelings while pursuing the individualized design work. In addition, the designer should also take into account whether people can accept it physically and mentally in designing the works. If the designed works only pursues the strange style and it wants to rely on the strange design to attract consumers without investigating what type of works the consumers truly like, the finally designed work can not be accepted by people, it can not be called successful works of art.

Before the design of products, designers should firstly make clear that the ultimate goal of the designed artwork is to be loved by consumers. That is to say the work of art is designed and produced for the demands. The first attribute of art is its market-oriented feature. The individualized products should not only serve as an appreciation product. Only when the designed products are produced to the finished products and put into use can it be kept in mind by the public. Such works of art can be called as the individualized product, which will not gradually become meaningless furnishings.

\section{Value of Individualized Pursuit of Artistic Design}

The art design works should not only have the characteristics of unity of culture and nature, but also should have the important value of aesthetic and practical unity. The art works with real values have a strong promoting role to the development of the entire society and culture. The individuality of the art design has the cultural values of the following aspects.

Experienced designers are aware that most of the inspiration for art design comes from real life that is closely related to people's lives, and can show the local cultural characteristics of the origin of art works. This type of art design works has valuable historical and cultural value. In contemporary society, the individuality of the product has always been the goal of the designers; all the designers want to be able to design the artworks with the characteristics of the times. In the design process of the works, the designers tend to be integrated into the lives of the local people in order to integrate the spirit of the local culture into their designed works of art and better serve the consumers.

At present, the pursuit of their own unique personality has become the mainstream idea, so the individualized design of art is also the main goal pursued by people. Now most people have been able to meet their own material life, so more and more people begin to care about their spiritual world. Designers should think more and us their own way to meet people's needs for spiritual life. The traditional and immutable design has been well known; too familiar design will make people have aesthetic fatigue. Once the boredom is produced, it will reduce the interest in art design products. Therefore, designers should add more local characteristics of culture in the works of art, enhance the works' observability, give people the brand-new visual experience and meet the spiritual needs of the masses, so as to obtain the favor of more consumes.

Art design needs to pay attention to the harmony with the surrounding environment. If the artistic creation affects the surrounding environment, this artwork is difficult to be recognized by consumers. After all, modern people attach more and more importance to environmental protection. Therefore, in the creation, designers must take into account whether the works will threaten the surrounding environment. Only works that do not harm the environment have ecological value. In the process of creation, there may be over-exploitation of the situation. The art works got by destructing the surrounding environment ill affect the possibility of sustainable development of the human society. This type of work is bound not to be recognized by the people.

Besides its own unique ornamental feature, the art design works should also avoid the boredom of products in the production process. Once the consumers have a sense of boring, it is difficult to produce influence in society, which will hinder the improvement of the level of artistic design work. Only when the designers pursue the social value of artwork in design can it gain the consumer' 
recognition of its concept and meet the consumers' demand for the works of art.

\section{Conclusion}

While pursing efficient production, people should also pay attention to the individuality of works of art. With the continuous development of society, the cultural areas should also be more and more diversified. At present, China's economic development is facing a new era of reform innovation and economic transformation. De-capacity, de-lever, de-storage and cost reduction and improvement of weak links are the inevitable trend of economic and social development. In the future, China's market will enter an age dominated by individuality. Therefore, designers need to strengthen their cultural connotation. Only by doing this can they keep creating the individualized aesthetic design works that meet people's aesthetics, so as to promote the rapid stable and healthy development of China's economy.

\section{References}

[1] Li Xiao. Research on the Value of Individualized Pursuit of Art Design [J]. Value Engineering, 2014 (4)

[2] Yao Wenting. On the Value of Individualized Pursuit of Art Design [J]. China Packaging Industry, 2014 (2)

[3] Pan Qin, Yang Lin.A Brief Analysis of Chinese Art Design Education [J]. Packaging World, $2013(02)$. 